\title{
Diurnal variations of humidity and ice water content in the tropical upper troposphere
}

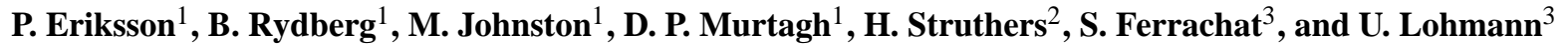 \\ ${ }^{1}$ Department of Earth and Space Sciences, Chalmers University of Technology, Gothenburg, Sweden \\ ${ }^{2}$ Department of Applied Environmental Science, Stockholm University, Sweden \\ ${ }^{3}$ Institute of Atmospheric and Climate Science, ETH Zurich, Switzerland
}

Received: 27 March 2010 - Published in Atmos. Chem. Phys. Discuss.: 3 May 2010

Revised: 15 November 2010 - Accepted: 30 November 2010 - Published: 6 December 2010

\begin{abstract}
Observational results of diurnal variations of humidity from Odin-SMR and AURA-MLS, and cloud ice mass from Odin-SMR and CloudSat are presented for the first time. Comparisons show that the retrievals of humidity and cloud ice from these two satellite combinations are in good agreement. The retrieved data are combined from four almost evenly distributed times of the day allowing mean values, amplitudes and phases of the diurnal variations around $200 \mathrm{hPa}$ to be estimated. This analysis is applied to six climatologically distinct regions, five located in the tropics and one over the subtropical northern Pacific Ocean. The strongest diurnal cycles are found over tropical land regions, where the amplitude is $\sim 7 \% \mathrm{RHi}$ for humidity and $\sim 50 \%$ for ice mass. The greatest ice mass for these regions is found during the afternoon, and the humidity maximum is observed to lag this peak by $\sim 6 \mathrm{~h}$. Over tropical ocean regions the variations are smaller and the maxima in both ice mass and humidity are found during the early morning. Observed results are compared with output from three climate models (ECHAM, EC-EARTH and CAM3). Direct measurementmodel comparisons were not possible because the measured and modelled cloud ice masses represent different quantities. To make a meaningful comparison, the amount of snow had to be estimated from diagnostic parameters of the models. There is a high probability that the models underestimate the average ice mass (outside the 1- $\sigma$ uncertainty). The models also show clear deficiencies when it comes to amplitude and phase of the regional variations, but to varying degrees.
\end{abstract}

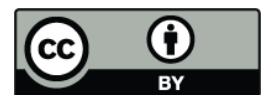

Correspondence to: P. Eriksson (patrick.eriksson@chalmers.se)

\section{Introduction}

Atmospheric water vapour is the dominant greenhouse gas in the Earth's atmosphere, and the amount and distribution will respond to changes in temperature, micro-physical processes, and atmospheric circulation (IPCC, 2007). Humidity changes in the tropical upper troposphere are of particular concern, since they are less well understood and have a stronger top of the atmosphere radiative impact than for other regions of the atmosphere (Held and Soden, 2000). Tropical upper tropospheric ice clouds, intimately connected to the water vapour, also have a strong top-of-the-atmosphere radiative impact (Harries, 2000). Thus, in order to accurately predict the future climate of Earth, it is critical to understand the processes which control the water budget and determine the distribution of water vapour and clouds in the tropical upper troposphere. For example, it is important to understand whether the moistening of the upper troposphere by deep convection partly occurs through evaporation of cirrus anvil clouds (Tian et al., 2004), or can be understood as vertical transport of water vapour alone (Soden, 2004). The consensus seems to be the latter (John and Soden, 2006; Sohn et al., 2008; Sherwood et al., 2010). However, if micro-physical processes are important for the moistening, the uncertainty in climate model simulations of the water vapour feedback increases as the confidence in the models' treatment of such processes is low (IPCC, 2007). Studies of diurnal cycles have been, and should continue to be, important for this discussion.

Satellite remote sensing is a useful tool for understanding atmospheric processes and evaluating climate model simulations. There have been several measurement studies of the diurnal cycle of tropical convective clouds and

Published by Copernicus Publications on behalf of the European Geosciences Union. 
humidity. Most of these studies are based on geostationary infrared (IR) data (e.g. Soden, 2000; Tian et al., 2004; Chung et al., 2007), but also combinations of IR and radar data from the Tropical Rainfall Measuring Mission (Hong et al., 2006; Liu and Zipser, 2008a) as well as IR and passive microwave measurements (Zelinka and Hartmann, 2009) have been used. Typically, IR brightness temperatures at $6.7 \mu \mathrm{m}$ are used to estimate the clear sky mean relative humidity between 500 and $200 \mathrm{hPa}$ (Soden and Bretherton, 1993), and various thresholds of the $11 \mu \mathrm{m}$ window channel are used to estimate occurrence frequencies of various cloud types (e.g. deep convective clouds $T_{11}<220 \mathrm{~K}$, and cirrus anvils clouds $220 \mathrm{~K}<T_{11}<260 \mathrm{~K}$ ). It has been demonstrated that a noticeable diurnal cycle of both deep convective clouds, high cold clouds, and upper tropospheric humidity (UTH) is present over land and ocean regions associated with convective activity (Hong et al., 2006; Chung et al., 2007). The UTH is observed to lag the peak of high cloud cover by several hours which, in turn, lags the peak of deep convective cloud occurrence (Horváth and Soden, 2008; Sohn et al., 2008; Zelinka and Hartmann, 2009).

Geostationary satellites are most suitable for studies of diurnal cycles, but their IR (and optical) sensors provide only an indirect estimate of the properties of deep convective clouds because they primarily observe cloud top temperatures (Garrett et al., 2009), and provide little or no information of the interior of the clouds. Additionally, humidity can only be retrieved for cloud free conditions.

To complement earlier studies, this paper focuses on studying the diurnal cycle of upper tropospheric water by combining measurements from three sensors operating in the $\mathrm{mm}$ and sub-mm part of the wavelength spectrum. The Odin Sub-Millimetre Radiometer (SMR, Murtagh et al., 2002) and the AURA Microwave Limb Sounder (MLS, Waters et al., 2006) provide measurements of humidity for both clear and cloudy sky conditions. CloudSat (Stephens et al., 2002) and Odin-SMR (Eriksson et al., 2007, 2008; Rydberg et al., 2009) provide measurements of cloud ice mass. The measured signals by CloudSat and Odin-SMR are related to the amount of cloud ice mass in the clouds. All three instruments are placed in polar sun-synchronous orbits with tropical local observation times of 1:30-1:40 a.m./p.m. for CloudSat and AURAMLS, and around 6:00 a.m./p.m. for Odin-SMR.

Differences in night and daytime observations of cloud and water vapour have been reported for CloudSat (Liu and Zipser, 2008b) and AURA-MLS (Liu and Zipser, 2009). In addition, the CloudSat and AURA-MLS ice mass products have been compared with climate model output (Waliser et al., 2009; Wu et al., 2009), although the ice mass diurnal cycle was not within the scope of these studies.

The atmospheric layer considered here is approximately centred around $200 \mathrm{hPa}$, and the focus is somewhat higher in the atmosphere than previous UTH studies based on IR data (covering 500-200 hPa). The main reason for studying this particular layer is that the Odin-SMR systematic un- certainties are smallest for this layer (Ekström et al., 2007), but can also be motivated for other reasons. The longwave cloud feedback in climate models is controlled by changes around $200 \mathrm{hPa}$ (Zelinka and Hartmann, 2010). The evaporation of clouds can only have a marginal effect on the humidity at lower altitudes as the ice mass is low in relative terms (John and Soden, 2006), but starting at about $200 \mathrm{hPa}$ the ice mass is significant or even dominating (Ekström and Eriksson, 2008), and cloud micro-physics could potentially be important at higher altitudes.

The combination of water products from Odin-SMR, AURA-MLS, and CloudSat offers a new possibility to study the diurnal variations of the water budget in the upper troposphere. However, as these polar orbiting satellites do not allow us to follow the time evolution of individual convective systems, only the climatology of the water in the tropical upper troposphere can be studied. Climatological means from each instrument provide four almost evenly distributed values during the day allowing for the study of the diurnal mean, amplitude and phase of water variations in the tropical upper troposphere.

A second objective of this paper is to evaluate whether three climate models (EC-EARTH, ECHAM, and CAM3) are capable of realistically capturing the diurnal variation of water in the tropical upper troposphere, as observed by the combination of satellite instruments. To build confidence in climate models' ability to accurately project future climate, it is desirable to evaluate the model performance at various shorter timescales through comparison with appropriate measurements (IPCC, 2007). In the tropics, the solar diurnal cycle is one of the basic forcing modes of the climate system and, as such, a climate model's response to this forcing should be a key test of the physical parametrisations used in the model (Slingo et al., 2003). Particularly over tropical land, accurate simulation of the diurnal cycle in the atmosphere is critical for the realistic simulation of the water and energy budget at the Earth's surface (Yang and Slingo, 2001). Model simulated diurnal variability of several parameters has previously been compared with various measurements, (e.g. Dai and Trenberth, 2004; Tian et al., 2004). These comparisons found that models had difficulty in reproducing the mean, amplitude and diurnal phase of parameters related to upper tropospheric water, such as UTH and cloud cover. The novelty of the comparison shown here is the unique combination of satellite measurements to determine the diurnal variation and the fact that the diurnal cycle of ice water content is included for the first time. 


\section{Data}

\subsection{Odin-SMR}

\subsubsection{Observations}

The Odin satellite was launched in February 2001 into a $600 \mathrm{~km}$ quasi-polar sun-synchronous orbit with an ascending node around 18:00 h local time. The payload includes the first space-borne sensor for atmospheric sub-mm observations, Odin-SMR. This limb sounding instrument measures thermal emission at frequencies around $500 \mathrm{GHz}$. The atmospheric signal is recorded through a $1.1 \mathrm{~m}$ telescope, singlesideband heterodyne receivers, and two auto-correlation spectrometers with $800 \mathrm{MHz}$ bandwidth. Further information can be found in Murtagh et al. (2002) and Ekström et al. (2007).

Odin's observation time has been time-shared between astronomy, stratospheric, and mesospheric modes. The retrievals of upper tropospheric ice water content (IWC) and relative humidity w.r.t. ice (RHi) considered are based on radiances collected by the stratospheric mode of Odin-SMR from the time period 2002-2009.

\subsubsection{Retrieval approach}

The retrieval of upper tropospheric IWC and RHi is not a part of the operational retrievals of Odin-SMR. These data are obtained from a Bayesian retrieval algorithm described in Rydberg et al. (2009). The approach is based on a retrieval database consisting of atmospheric states and simulated radiances. The atmospheric states in the retrieval database are created based on existing relevant a priori data. Most importantly, CloudSat allows the incorporation of detailed cloud structure information. However, relevant a priori data on the variability of tropical ice cloud particle size distribution (PSD) parameters were considered to be lacking. A main assumption made while generating the atmospheric states is that the PSD derived by McFarquhar and Heymsfield (1997) describes the tropical mean PSD.

Profiles of IWC and RHi are retrieved simultaneously. These profiles can be seen as weighted means of the states in the retrieval database. This database is common for the complete tropical region and all horizontal patterns are direct measurement information. Retrievals are performed for all atmospheric conditions (data lost only due to occasional calibration failures). For data affected by cloud scattering, the retrieval reflects the a priori assumption of a RHi of $\approx 100 \%$ inside cloudy regions.

Only retrievals from around $13 \mathrm{~km}$ in altitude are considered here. The vertical resolution is $\sim 5 \mathrm{~km}$, and the size of the footprint is $\sim 45$ and $2 \mathrm{~km}$ in the along- and acrosstrack direction, respectively. Only regional RHi average values are used here and the impact of random retrieval errors (estimated to be $17 \% \mathrm{RHi}$ ) is less critical. Some compen- sation of the a priori influence found in individual retrievals can be made (Rydberg et al., 2009) and it has been applied here. The systematic retrieval error for RHi data should not exceed a $30 \%$ relative error, dominated by calibration and temperature errors (Ekström et al., 2007) and cloud interference (Rydberg et al., 2009). Particle size assumptions and cloud inhomogeneity effects dominate both the random and systematic error budget for IWC, and the combined error has been estimated to be $65 \%$ and $40 \%$, respectively.

\subsection{CloudSat}

\subsubsection{Observations}

CloudSat is a satellite designed to measure the vertical structure of clouds from space (Stephens et al., 2002). The satellite has a 13:31 h local time ascending node, sunsynchronous orbit at $705 \mathrm{~km}$ altitude. CloudSat carries a $94 \mathrm{GHz}, 0.16^{\circ}$ off-nadir-looking Cloud Profiling Radar which measures the power back-scattered by clouds as a function of distance from the radar. The standard data product consists of 125 vertical bins that are $240 \mathrm{~m}$ thick, while the vertical resolution of the radar is approximately $500 \mathrm{~m}$. Each profile is generated over a $160 \mathrm{~ms}$ integration time, giving a footprint resolution of approximately $1.3 \mathrm{~km}$ acrosstrack and $1.7 \mathrm{~km}$ along track. The minimum detectable equivalent radar reflectivity is approximately $-30 \mathrm{dBZ}$ and the dynamic range is $70 \mathrm{dBZ}$. 2B-Geoprof radar reflectivity profiles from 2006-2009 are considered.

\subsubsection{Retrieval approach}

As for passive observations, the CloudSat IWC retrieval is affected by the assumed PSD. In fact, this is the main retrieval uncertainty (at lower altitudes, the discrimination between liquid and ice particles is a second critical issue). The assumptions made in the official CloudSat retrievals cannot be transferred to the Odin-SMR inversions. Instead, alternative CloudSat retrievals were performed, following the PSD applied for Odin-SMR. The approach is straightforward. Radar reflectivities are calculated for combinations of IWC and temperature, assuming Mie scattering and that the particle sizes follow McFarquhar and Heymsfield (1997). These data are used as a look-up table for the retrieval, where CloudSat reflectivities are mapped to IWC values (with temperature taken from the ECMWF-aux product). See further Eriksson et al. (2008), where also a comparison to the official retrieval products is found.

This alternative retrieval does not decrease the systematic error; it could very well increase it. However, this approach ensures that systematic errors between the CloudSat and Odin-SMR IWC datasets are correlated as much as possible. This avoids the problem of differences in PSD assumptions causing spurious diurnal cycles. 
The spatial resolution is important when comparing IWC retrievals (Wu et al., 2009), and the CloudSat IWC data are averaged to match the much poorer resolution of Odin-SMR. The (vertical) averaging kernel of Odin-SMR IWC retrievals changes with cloud conditions, but just the ensemble mean averaging kernel has been estimated. For this reason, a simple averaging was preferred. No Odin-SMR kernel was applied, instead a simple averaging over $5 \mathrm{~km}$ vertically and $40 \mathrm{~km}$ horizontally was performed to match the spatial resolution of Odin-SMR in a basic, but robust, manner.

\subsection{AURA-MLS}

\subsubsection{Observations}

AURA-MLS is a passive instrument consisting of seven radiometers operating at five spectral bands from near $118 \mathrm{GHz}$ to $2.5 \mathrm{THz}$ (Waters et al., 2006), although only data from three radiometers are considered here (two near 118 and one near $190 \mathrm{GHz}$ ). The two $118 \mathrm{GHz}$ receivers at orthogonal polarisations are single sideband, while the $190 \mathrm{GHz}$ receiver is double sideband. Atmospheric signals for the 118- and $190-\mathrm{GHz}$ radiometers are collected by a three-reflector offset antenna system that vertically scans the limb. The primary mirror dimension is $1.6 \mathrm{~m}$ projected in the vertical direction at the limb tangent point. The Aura satellite is in a sun-synchronous orbit at $705 \mathrm{~km}$, with a local time ascending node around 13:35. Version 2.2 RHi retrievals from 2004 to 2007 are considered.

\subsubsection{Retrieval approach}

The retrieval process uses an iterative scheme in an optimal estimation framework (Livesey et al., 2006). Humidity and temperature profiles are retrieved from the $183 \mathrm{GHz}$ water vapour line and $118 \mathrm{GHz}$ oxygen line, respectively. Relative humidity profiles are obtained by combining temperature and humidity retrievals. The vertical resolution is $\sim 5 \mathrm{~km}$ and the estimated $2-\sigma$ accuracy and precision are $\sim 35 \%$ and $45 \%$, respectively (Read et al., 2007).

\subsection{ECHAM}

\subsubsection{Model description}

The ECHAM5 simulations have been carried out in T42 horizontal resolution $(\sim 2.8 \times 2.8$ degrees $)$ on 19 vertical levels with the model top at $10 \mathrm{hPa}$ and a timestep of $30 \mathrm{~min}$. All simulations used climatological sea surface temperature and sea-ice extent. The simulation has been integrated for 5 years after a 3-month spin-up with an output frequency of $3 \mathrm{~h}$.

The version of ECHAM5 used in this study has been described in Lohmann and Hoose (2009). It includes the twomoment aerosol scheme HAM that predicts the aerosol mixing state in addition to the aerosol mass and number concentrations (Stier et al., 2005). The size-distribution is rep- resented by a superposition of log-normal modes including the major global aerosol compounds sulfate, black carbon, organic carbon, sea salt and mineral dust.

\subsubsection{Model ice cloud and related processes}

The stratiform cloud scheme consists of prognostic equations for the water phases (vapour, liquid, and solid), bulk cloud micro-physics (Lohmann and Roeckner, 1996), and an empirical cloud cover scheme (Sundqvist et al., 1989). The micro-physics scheme includes phase changes between the water components and precipitation processes (autoconversion, accretion and aggregation). Moreover, evaporation of rain and melting of snow are considered, as well as sedimentation of cloud ice. It also includes prognostic equations of the number concentrations of cloud droplets and ice crystals and has been coupled to the aerosol scheme HAM (Lohmann et al., 2007). It assumes that cirrus clouds form by homogeneous freezing of supercooled solution droplets (Lohmann et al., 2008). Detrainment of cloud water and ice from convective clouds is a source for stratiform clouds. Rain and snow are treated diagnostically assuming that both raindrops and snow flakes that are not evaporated or sublimated, respectively, reach the surface within one time step.

\subsection{CAM3}

\subsubsection{Model description}

The Community Atmospheric Model 3 (CAM3), described by Collins et al. (2006), is the sixth generation of the community atmospheric general circulation model released by the National Center for Atmospheric Research. The atmospheric model is integrated together with the Community Land Model (Bonan et al., 2002; Oleson et al., 2004), a thermodynamic sea ice model (Briegleb et al., 2004), and either a data ocean or a slab-ocean model for equilibrium climate response studies. The set of sub-grid scale physical parametrisations used in the model is documented in Collins et al. (2006). Further information can be found at: http: //www.ccsm.ucar.edu/models/atm-cam/docs/description/.

The version of CAM3 employed here used the Eulerian dynamical core at T42 spectral truncation, which is approximately $2.8 \times 2.8$ degrees on a Gaussian grid and a hybrid $\eta$ coordinate with 26 levels in the vertical. The model was run from September 2001 to January 2009 using sea surface temperatures and sea ice fractions from the data set of Hurrell et al. (2008), and the output frequency time was $3 \mathrm{~h}$.

\subsubsection{Model ice cloud and related processes}

The treatment of micro-physics and cloud condensate have been substantially revised in CAM3 (Boville et al., 2005). The diagnostic cloud-water scheme used in CAM2 and Community Climate Model version 3 (CCM3) has been replaced 
by the single-moment prognostic cloud-water parametrisation of Rasch and Kristjansson (1998), updated by Zhang et al. (2003). CAM3 includes separate evolution equations for the liquid and ice-phase condensate. The parametrisation of deep convection is based on the work of Zhang and McFarlane (1995), but extended such that the convective cloud fraction is explicitly included in the model. Both deep and shallow convection parametrisations detrain cloud condensate directly into the stratiform clouds.

The settling velocities for liquid and ice-phase constituents are computed separately as functions of their respective effective radii. Small ice particles are assumed to fall like spheres according to the Stokes equation. The fall speeds of larger ice particles are calculated following Locatelli and Hobbs (1974). The fall velocities of liquid drops are treated using the Stokes equation for their entire size range. The amount of snow was, for this study, estimated from the diagnostic parameters of the rate of production of precipitation and the rate of evaporation of precipitation.

\subsection{EC-EARTH}

\subsubsection{Model description}

Project EC-EARTH aims to develop a new Earth System Model that will be used, and further developed, by several European countries. These countries are exclusively member states of the European Centre for Medium-Range Weather Forecasts (ECMWF). The resulting model consists of an atmospheric general circulation model (Integrated Forecast System, IFS), an ocean general circulation model (Nucleus for European Modelling of the Ocean, NEMO), a sea-ice model, a land model, and an atmospheric chemistry model, with the possibility of adding more sub-models. EC-EARTH was configured, for this study, with a circa $1 \times 1$ degree horizontal resolution and 62 vertical levels (T159L62) using prescribed sea surface temperatures. The model was run for 2001-2008 with an output frequency time of $3 \mathrm{~h}$.

\subsubsection{Model ice cloud and related processes}

The cloud scheme used in IFS cycle 31r1, and also in this study, is described in detail in Tiedtke (1993). Liquid and ice cloud water are treated as prognostic variables in the model. Frozen precipitation, however, is a diagnostic variable that is extracted via auto-conversion from ice water content and assumed to fall to the ground between time steps.

The amount of frozen precipitation at each model level was estimated by converting the fluxes of frozen precipitation to a representative mass ratio. In order to achieve this, an assumption of a bulk fall speed of $1 \mathrm{~ms}^{-1}$ was assumed. Both the convective and stratiform frozen precipitation were then added to the IWC to obtain a total IWC.

\subsection{ERA-Interim}

ERA-Interim is the successor to ERA-40 (Uppala et al., 2005), and is a global atmospheric reanalysis of the period 1989 to present. The IFS version Cy31r1/2 is common to both EC-Earth and ERA-Interim. EC-Earth's IFS cycle, however, contains physics packages from later IFS cycles. ERA-Interim includes assimilated measurements but the measurements considered in this study are not included. Monthly mean 6-hourly data covering 2001-2009 are considered. A motivation for including ERA-Interim data in the comparison is that it serves as a valuable reference to both the considered measurements and EC-EARTH.

\section{Observation results}

The focus of this section is to compare and examine the observations of water in the tropical upper troposphere. The upper tropospheric layer considered is located around $190 \mathrm{hPa}$ $(12.75 \mathrm{~km})$ in altitude, with a vertical extension of $\sim 5 \mathrm{~km}$.

This layer is chosen because the Odin-SMR retrieval accuracy of both RHi and IWC is relatively good at this layer (Ekström et al., 2007; Rydberg et al., 2009). AURA-MLS retrieved RHi are interpolated to $190 \mathrm{hPa}$, and have roughly the same vertical resolution as Odin-SMR. Thus, no further modification is made to this product. CloudSat retrieved IWC profiles are averaged vertically and horizontally as described in Sect. 2.2.2

Multi year seasonal mean fields from the boreal winter and spring period are considered. This period is chosen to be studied because during this period Odin-SMR provides a more uniform geographic coverage. A problematic clustering of the observations occurs during the summer period.

Although Odin-SMR has been in operation for a longer time period than both AURA-MLS and CloudSat, the Odin dataset is much smaller than the other two. Thus, a relatively broad averaging of data is considered due to the limited size of the Odin dataset. All data have been averaged in the following way: First, an averaging over $1.5^{\circ} \times 1.5^{\circ}$ in latitude and longitude was performed for the different local time winter and spring measurements. Then a running mean averaging with a resolution of $9^{\circ} \times 9^{\circ}$ in latitude and longitude is performed for the winter and spring measurements. The winter and spring averages are then combined.

\subsection{Relative humidity}

Odin-SMR and AURA-MLS retrieved upper tropospheric RHi have earlier been shown to compare well, with differences between regional averages of less than 10\% (Ekström et al., 2008; Rydberg et al., 2009). Figure 1 shows multi-year, winter and spring, retrieved RHi fields at around $13 \mathrm{~km}$ in altitude from Odin-SMR and AURA-MLS from their night/morning/noon/afternoon measurements. The geographical patterns of RHi are in good agreement between 


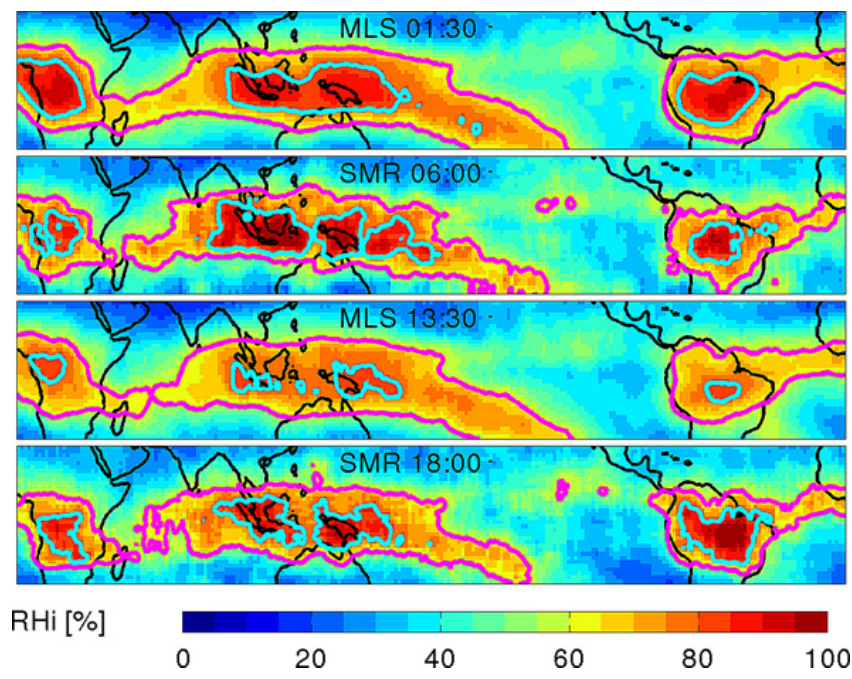

Fig. 1. Multi-year boreal winter and spring RHi fields around $190 \mathrm{hPa}$ derived from Odin-SMR and AURA-MLS. The magenta and cyan contour lines mark regions with $\mathrm{RHi}>60 \%$ and $\mathrm{RHi}>80 \%$, respectively. Data averaging is described in the text.

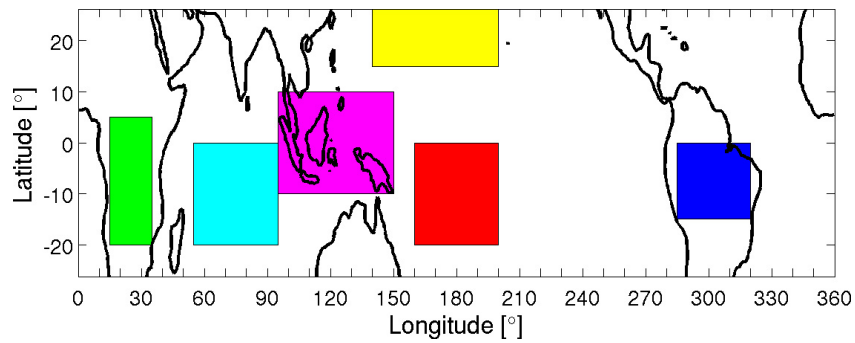

Fig. 2. Definition of selected regions (green = Africa, cyan = Tropical Indian, magenta $=$ Maritime Continent, yellow $=$ North Pacific, red $=$ Tropical Pacific, and blue $=$ South America $)$.

the datasets. High RHi is found over regions associated with strong convection; Central Africa, South America and the maritime continent. In general, RHi decreases with increasing distance from these convectively active regions. Low RHi are found in tropical regions associated with large scale descent, as, for example, the North Pacific. Figure 1 illustrates that the humidity distribution in the tropical upper troposphere is controlled by several factors, including convective systems, detrainment of water vapour and condensed water from those systems, and large scale atmospheric circulation.

Figure 1 shows contour lines to highlight consistencies and possible differences between the datasets. Maybe the most clear difference is that a band of RHi> $60 \%$ along the South Pacific convergence zone is significantly narrower for OdinSMR, for an unknown reason. There are relatively small temporal variations in the $\mathrm{RHi}=60 \%$ contours compared to the
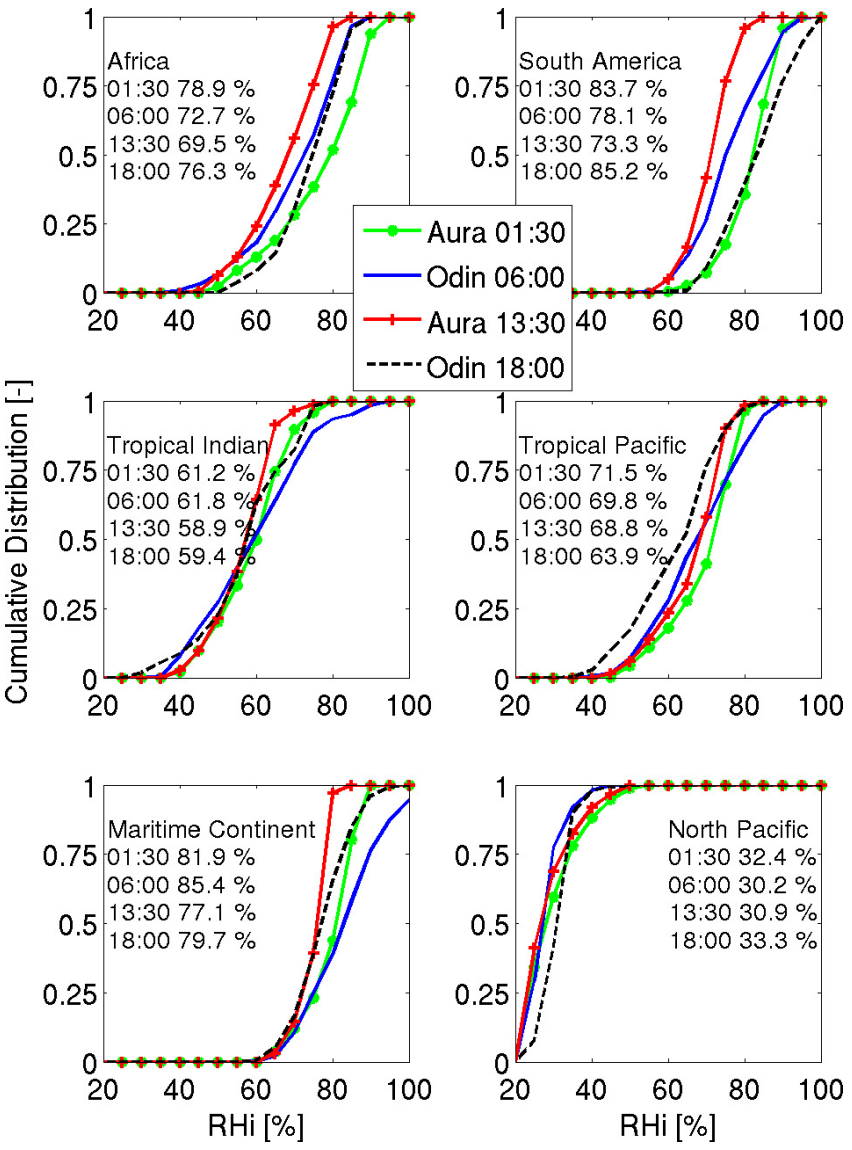

Odin 18:00
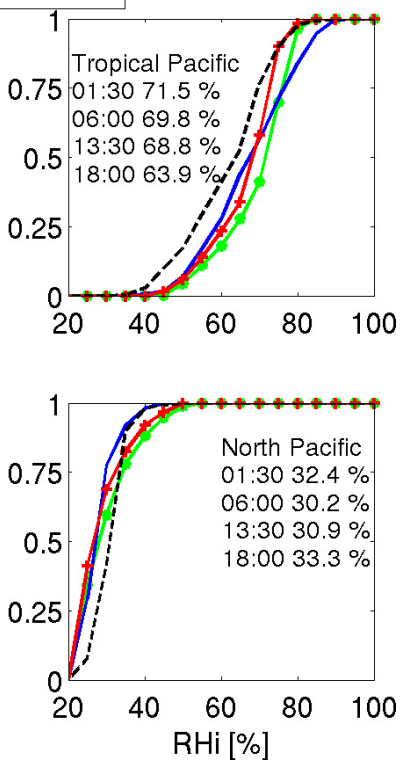

Fig. 3. RHi cumulative distributions of the data shown in Fig. 1 for various regions as defined in Fig. 2. The text in the panels gives the average for each distribution.

$\mathrm{RHi}=80 \%$ contours. The area enclosed by the RHi $=80 \%$ contour is a minimum around noon and maximises in the early evening over land and early morning over the maritime continent. This phase is in line with previous studies, e.g. (Chung et al., 2007).

Six climatologically varying regions were defined, shown in Fig. 2. In Fig. 3 the datasets are compared in more detail for these regions, in order to search for any obvious systematic bias and spurious features. The distributions and mean values over the North Pacific region (lower right panel), where small diurnal variations are expected, are in good agreement. Thus any possible bias between the measurements should be within a few \%RHi for dry regions.

For the wet regions, Odin-SMR shows less steep distributions. This should mainly be a combined effect of that both the retrieval precision is poorer and the number of measurements is lower for Odin-SMR; some impact of natural variability and measurement errors remain after the spatial averaging. This corresponds to the fact that the RHi fields in Fig. 1 are less smooth for Odin-SMR. In fact, the distribution of Odin-SMR for the Maritime Continent at 06:00 shows that 


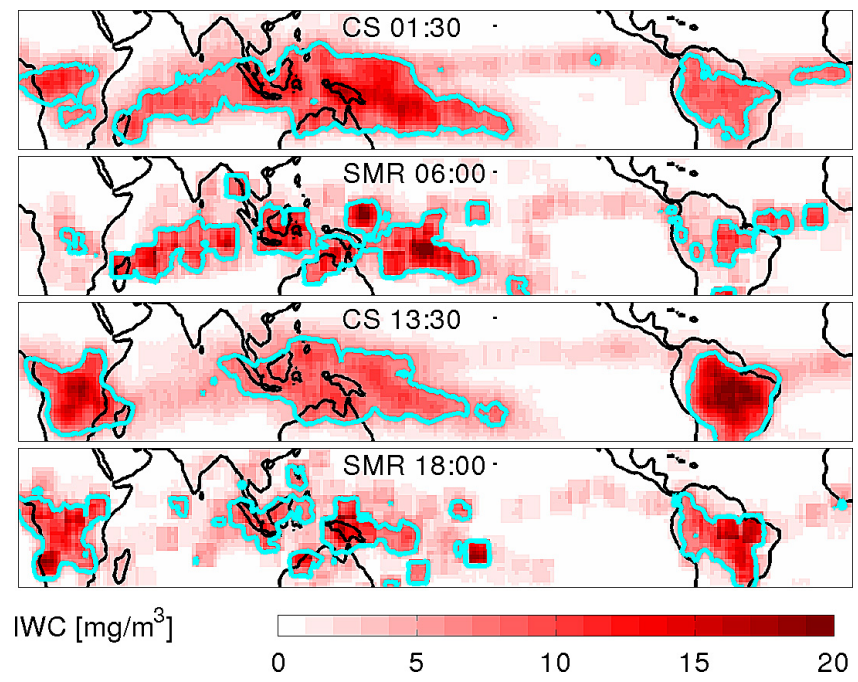

Fig. 4. Multi-year boreal winter and spring IWC fields around $190 \mathrm{hPa}$ derived from Odin-SMR and CloudSat. The cyan contour line marks regions with IWC $>6 \mathrm{mgm}^{-3}$. Data averaging is described in the text.

an average above $100 \%$ has been obtained for a part of the region. The retrieval database contains cases with a RHi above $100 \%$, but distributed in such way that "true" averages should not show super-saturation (though individual retrievals can have $\mathrm{RHi}>100 \%$ ). Our interpretation is then that the distribution differences are mainly caused by remaining random components in the Odin-SMR data, and less indications on systematic deviations.

The poorer statistical basis of Odin-SMR is also the reason as to why the analysis is restricted to averages over complete regions. The mean values in Fig. 3 are the actual data that will be used below. These values give a single diurnal maximum (and minimum) for all regions, which should be the expected pattern. This can only be achieved if systematic errors are small, or common, for both instruments.

In summary, we confirm from earlier studies that regional averages of RHi from Odin-SMR and AURA-MLS are in good agreement, with a bias possibly considerably smaller than the $10 \%$ RHi previously reported. However, the good agreement shown here is only valid for this particular layer, and a lower consistency has been shown for a layer around $127 \mathrm{hPa}$ (Ekström et al., 2008). We conclude that for the $190 \mathrm{hPa}$ layer some of the difference is due to diurnal variations, and that it could be attempted to combine the datasets for a study of diurnal variations.

\subsection{Ice water content}

Figure 4 is similar to Fig. 1 but shows retrieved IWC from Odin-SMR and CloudSat. The overall patterns of ice mass agree well in general between the datasets, although the Odin dataset is noisier than the CloudSat dataset. As expected,

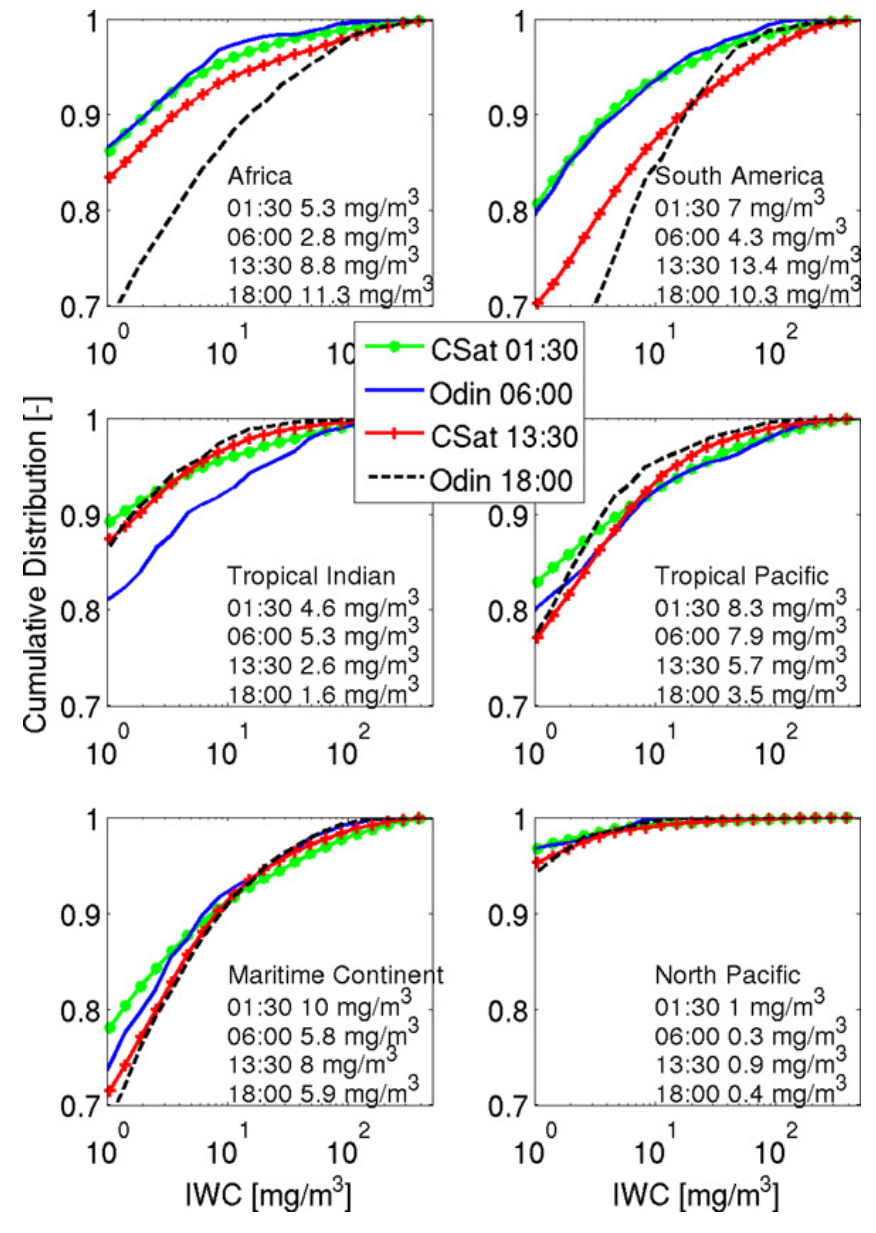

Fig. 5. IWC distributions of the data shown in Fig. 4 for various regions as defined in Fig. 2. The text in the panels gives the average for each distribution.

regions with high mean IWC and RHi match quite closely, and no, or low, ice mass is found over the drier regions. Over tropical land convective regions, the concentration of ice mass appears to be higher during the day compared to nighttime. The opposite is true for convective ocean regions. These phase relationships are consistent with previous studies on occurrence frequencies of deep convective clouds (e.g. Hong et al., 2006). The contour lines show regions with IWC $>6 \mathrm{mgm}^{-3}$. Although Odin data are noisier, these regions show a fairly consistent "time evolution" pattern. Thus, the datasets are considered to be consistent, with no obvious bias apparent at this stage.

As ice mass values have a large dynamic span and are not Gaussian distributed, care must be taken when analysing mean values. Figure 5 shows retrieved IWC distributions for various regions. Over Africa and S. America, the distributions of CloudSat 13:30 and Odin-SMR 18:00 show that significantly more ice mass is retrieved from those measurements than from the night and morning. The frequency of IWC $>100 \mathrm{mgm}^{-3}$ is greatest from CloudSat 
13:30 measurements, whereas Odin-SMR 18:00 reports a significantly greater frequency of IWC $>10 \mathrm{mgm}^{-3}$.

Over the tropical ocean regions the distributions show less variation than over tropical land. The tendency is that Odin-SMR 18:00 reports a relative low frequency of IWC $>10 \mathrm{mgm}^{-3}$ and low mean value. Over the Maritime continent mean IWC is higher for CloudSat than for OdinSMR. Over the North Pacific there is basically very little ice mass.

The regional averages (text in Fig. 5) show a single diurnal maximum/minimum for four of the regions. One of the exceptions is the North Pacific region. A somewhat better sensitivity of CloudSat to thin clouds could explain the systematic difference between the two sensors for this region. This issue is of smaller importance for other regions, where the average is controlled by clouds with high IWC. The other exception is the Maritime Continent region. This region covers both land and ocean areas, and a mix of two diurnal cycles is probably observed. This is discussed further below.

In summary, the distributions show realistic features and are consistent to previous observational studies. As variations also can be found in mean values, and no obvious bias can be found in the distributions, we consider that no strong bias is expected to be found in the variation of the mean values. It should be pointed out that a strong correlation in a possible IWC retrieval bias is expected due to the fact that the retrievals are based on the same micro-physical assumptions. This will be taken into account in the following sections.

\subsection{Diurnal variations}

In the previous sections, it was demonstrated that there is sufficient consistency in the different satellite products to consider studying the diurnal cycle by combining the datasets. In this section we will estimate mean values, amplitude and phase for the regions defined in Fig. 2.

To provide estimates of these variables we make a number of assumptions. The diurnal variations of both RHi and IWC $(x)$ are approximated by a diurnal harmonic

$x(t)=\bar{x}+A \cdot \cos \left(\frac{2 \pi}{24}(t-\phi)\right)+\epsilon$,

where $\bar{x}$ is the daily mean, $A$ the amplitude, $t$ the time (in hours), and $\phi$ the phase. The simple form assumed for the diurnal variation (Eq. 1) was chosen because the datasets provide only four separate time inputs per day. This precludes meaningful fitting of higher order diurnal terms. We derive the quantities in a weighted least square procedure. In this way an error covariance matrix takes into account the fact that the measurements considered are correlated and have different errors. We only take systematic retrieval uncertainties into account, as the retrieval precisions are negligible for the broad averages considered.

For RHi we assume that both Odin-SMR and AURA-MLS $1-\sigma$ retrieval systematic uncertainties are 10\% RHi. Ekström et al. (2007) derived a 30\% RHi worst case systematic error estimate for Odin-SMR, but treating the sources as independent we obtain a 1- $\sigma$ estimate of approximately $10 \%$ RHi. The assumed $10 \%$ RHi value is also consistent with a satellite derived RHi climatology comparison study by Ekström et al. (2008). We consider that the systematic errors for OdinSMR and AURA-MLS are uncorrelated but that their respective a.m. and p.m. systematic errors are strongly correlated (correlation coefficient of 0.9).

For Odin-SMR derived IWC there are three sources that dominate the systematic retrieval uncertainty. These are: (1) the assumed particle size distribution (PSD), (2) the assumed particle shapes and refractive index, and (3) cloud inhomogeneity effects, and estimated in Eriksson et al. (2007) to give rise to a systematic $1-\sigma$ uncertainty of $30 \%, 15 \%$, and $30 \%$, respectively. However, the Odin-SMR data considered were retrieved from an improved algorithm, presented in Rydberg et al. (2009), that treats cloud inhomogeneity effects more accurately. We assume that the corresponding systematic retrieval uncertainty now is $15 \%$. This yields an Odin-SMR total $1-\sigma$ retrieval uncertainty of $37 \%$. The CloudSat data are retrieved using identical micro-physical assumptions as for Odin-SMR. We assume that the systematic retrieval uncertainty related to the micro-physics will be identical as for Odin-SMR. However, cloud inhomogeneities are not considered to be a large retrieval issue for CloudSat, and we assume that no systematic error is introduced due to cloud inhomogeneities. This yields an estimated 1- $\sigma$ total retrieval uncertainty for CloudSat of $33 \%$. This value is consistent to the fact that the official IWC product from CloudSat is reported to have a bias less than $40 \%$ (Austin et al., 2009).

We assume that the PSD dependent systematic retrieval uncertainty for Odin-SMR pm measurements is correlated with the PSD uncertainty for all other measurements, e.g. CloudSat am measurements. A correlation coefficient of 0.9 is assumed. This level of correlation is assumed for all individual uncertainty sources ( 3 for Odin-SMR and 2 for CloudSat) between the am and pm measurements for all combinations of measurements. This results in Odin-SMR am and pm error correlation coefficient of 0.9, CloudSat am and pm error correlation coefficient of 0.9 , and Odin-SMR am/pm and CloudSat am/pm error correlation coefficient of 0.83 .

As the retrievals from Odin-SMR and CloudSat considered are based on the same PSD assumption, the systematic uncertainties are correlated. As a result, the diurnal mean values can not be determined very accurately. On the other hand, the correlations allow for accurate estimates of relative amplitudes $(A / \bar{x})$ and phases.

Results obtained for RHi are presented in Table 1. The amplitude is most significant over Africa and S. America $(\sim 6$ and $8 \% \mathrm{RHi}$ ), the maximum occurring in the early evening. The amplitude is about twice as large over tropical land than over tropical ocean region where the amplitude is below $\sim 3 \%$ RHi, but with uncertainties almost as great. The 
Table 1. Measured RHi diurnal variations estimate together with uncertainties $(1-\sigma)$.

\begin{tabular}{lccc}
\hline region & mean [\% RHi] & amplitude [\% RHi] & phase $[h]$ \\
\hline Africa & $74.3 \pm 6.9$ & $6.1 \pm 2.5$ & $23: 00 \pm 3.0$ \\
T. Indian & $60.3 \pm 6.9$ & $1.4 \pm 1.7$ & $04: 00 \pm 3.0$ \\
M. continent. & $81.0 \pm 6.9$ & $3.2 \pm 1.9$ & $04.30 \pm 3.5$ \\
N. Pacific & $31.7 \pm 6.9$ & $2.1 \pm 1.9$ & $21: 00 \pm 5.0$ \\
T. Pacific & $68.5 \pm 6.9$ & $3.0 \pm 1.8$ & $06: 00 \pm 4.0$ \\
S. America & $80.1 \pm 6.9$ & $7.9 \pm 2.8$ & $22: 00 \pm 3.0$ \\
\hline
\end{tabular}

maximum over ocean regions is estimated to be in the early morning.

The observations are in fair agreement with results from Chung et al. (2007), who reports a UTH peak around 02:0003:00 over tropical land (Africa), and a broad peak during the night is found over ocean (tropical Atlantic). Additionally, the reported amplitude over land $(\sim 2 \%)$ is about twice as large as the amplitude over oceans $(\sim 1 \%)$. The relatively large amplitude reported from this study compared to previously published results, can, in part, be explained by the fact that the regions considered here are centred over convectively active areas and a somewhat higher located altitude layer is here considered. The vertical layer considered is centred around $190 \mathrm{hPa}$, whereas UTH normally refers to 500$200 \mathrm{hPa}$.

Results obtained for IWC are presented in Table 2. Over Africa and South America the results are similar with relatively high mean values, amplitudes of $\sim 50 \%$ of the mean value and a maximum in the afternoon. The timing of the maximum is in line with e.g. Hong et al. (2006), who used data from the PR (Precipitation Radar) and VIRS (Visible and Infrared Scanner) onboard the Tropical Rainfall Measuring Mission. They noted that, over tropical land, the occurrence frequency of deep convective clouds peaks around 14-16 h local time according to the PR and 16-18 h local time according to VIRS $\left(T_{11}<210 \mathrm{~K}\right)$, and the occurrence frequency of high cold clouds $\left(210 \mathrm{~K}<T_{11}<235 \mathrm{~K}\right)$ peaks around $16-18 \mathrm{~h}$ local time (VIRS). See also Tian et al. (2004).

Over tropical Indian and Pacific ocean mean values are somewhat lower than over the land regions, and the maximum is estimated to be in the early morning. Hong et al. (2006) found a maximum in deep convective clouds around 04:00-06:00 (PR) and 05:00-07:00 (VIRS). Additionally they found that the peak of high cold clouds lags the peak of deep convective clouds by 7-9 h. However, as these clouds are expected to be remnants of deep convective clouds one would expect that some ice mass has evaporated or fallen out since the injection of the ice mass, so that the ice mass is lower around noon. This is also observed.

Over the Maritime continent Hong et al. (2006) found that the diurnal cycle of clouds can be understood as a combination of such cycles over land and ocean. This means that
Table 2. Measured IWC diurnal variations estimates together with uncertainties $(1-\sigma)$. The amplitude is given in fraction of the corresponding mean value (the column to the left). As the N. Pacific region can be significantly influenced by IWC values below the sensitivity limit of the instruments, the standard error estimation is not trusted for amplitude and phase, and these results are not used below.

\begin{tabular}{lccc}
\hline region & mean $\left[\mathrm{mgm}^{-3}\right]$ & relative amplitude $[--]$ & phase $[h]$ \\
\hline Africa & $6.4 \pm 2.4$ & $0.51 \pm 0.06$ & $18: 00 \pm 1.5$ \\
T. Indian & $4.6 \pm 1.5$ & $0.52 \pm 0.06$ & $05: 30 \pm 1.5$ \\
M. continent & $7.1 \pm 2.5$ & $0.11 \pm 0.09$ & $01: 00 \pm 4.0$ \\
N. Pacific & $0.4 \pm 0.2$ & $0.41 \pm ?$ & $08: 00 \pm ?$ \\
T. Pacific & $6.9 \pm 2.3$ & $0.28 \pm 0.06$ & $05: 00 \pm 2.0$ \\
S. America & $6.9 \pm 2.3$ & $0.38 \pm 0.07$ & $16: 00 \pm 2.0$ \\
\hline
\end{tabular}

one would expect to see relatively high IWC throughout the day and double maxima in IWC. However, this variation cannot be fully resolved by measurements from only four times during the day. We observe a high mean value and low amplitude, which to some extent agree with results from Hong et al. (2006).

\section{Model-data comparisons}

In this section we compare observed diurnal variations of RHi and IWC with corresponding results from climate models and ERA-Interim. The model data are averaged vertically to match the $\sim 5 \mathrm{~km}$ vertical resolution of the satellite data and all data inside each region (Fig. 2) are included in the final average. The model datasets cover different time periods, or have no direct time stamp (Sect. 2), but no restriction or matching in the time dimension has been made.

As for the satellite data, we consider the mean, amplitude, and phase inside the six regions. Mean values are strictly the mean value of the parameters for the different output times. Amplitude is half the difference between maximum and minimum value. The phase corresponds to the local time of the maximum value. The data from CAM3, ECHAM and EC-Earth have an output frequency of $3 \mathrm{~h}$, while for ERAInterim it is $6 \mathrm{~h}$ (Sect. 2). The model fields have all a relatively smooth time evolution and to restrict the analysis to data for the time of the satellite passages would not change the results in any important manner, but would require extensive work, to extract data for local times instead for common universal time steps.

\subsection{Relative humidity diurnal variations}

Figure 6 shows measured and modelled diurnal variations of RHi. Mean values from observations are in excellent agreement with ERA-Interim values which provide further confidence in the measurements. It is stressed that ERA does not assimilate the observations considered. 

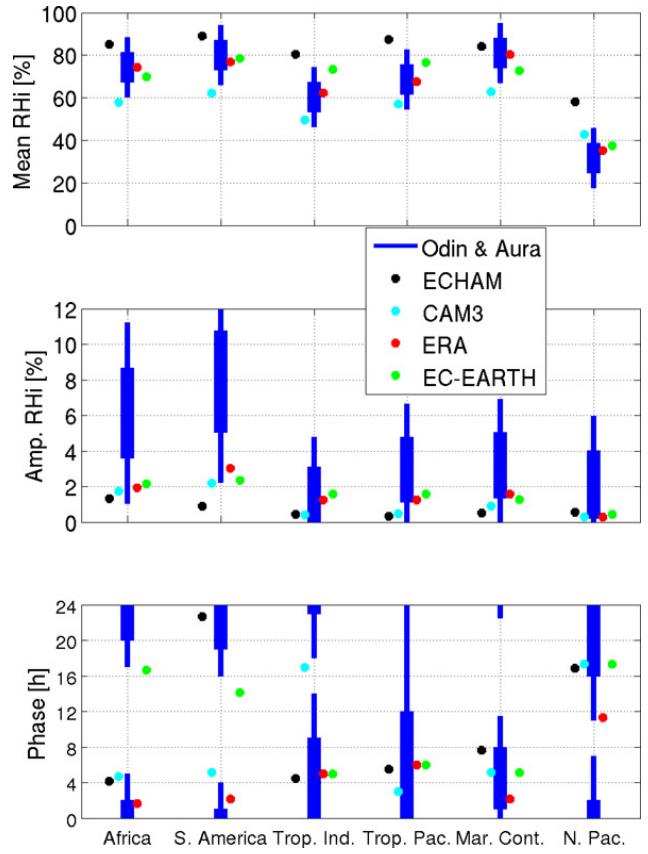

Fig. 6. Multi-year boreal winter and spring observed and simulated RHi diurnal variations around $190 \mathrm{hPa}$ for the regions defined in Fig. 2. The thick part of the blue lines corresponds to $\pm 1-\sigma$ and the thin part to $\pm 2-\sigma$ of the satellite estimates.

ECHAM is throughout wetter than best measurement estimate, while CAM3 is drier except for N. Pacific. The dynamical range in RHi of CAM3 and ECHAM data is significantly lower than the measured. Thus, these models seem to underestimate the tropical geographical RHi variability. ECEARTH data fit within the measured 2- $\sigma$ uncertainty, and are close to ERA values. This indicates that the IFS does not have to rely on assimilated measurements to produce realistic RHi mean values. This in its turn gives strong support to the relatively recently implemented parametrisation for ice supersaturation in IFS by Tompkins et al. (2007). EC-EARTH simulations were performed on a $\sim 3$ times finer horizontal resolution than for ECHAM and CAM3, which might be one reason for why EC-EARTH better captures the geographical RHi variability.

All models show a greater amplitude over land than over ocean regions, which is consistent with the measurements. However, the observed amplitudes $( \pm 1-\sigma)$ over land are in general much greater than that modelled. This indicates that the strength of convection over land is too weak in the models.

Estimated and ERA phases are in reasonable agreement, beside for the North Pacific region. The observed and modelled phases are consistent over the ocean and maritime continent regions, beside CAM3 for Tropical Indian. ECEARTH follows the measured phases closely except over the pure land regions, where EC-Earth deviates from all other
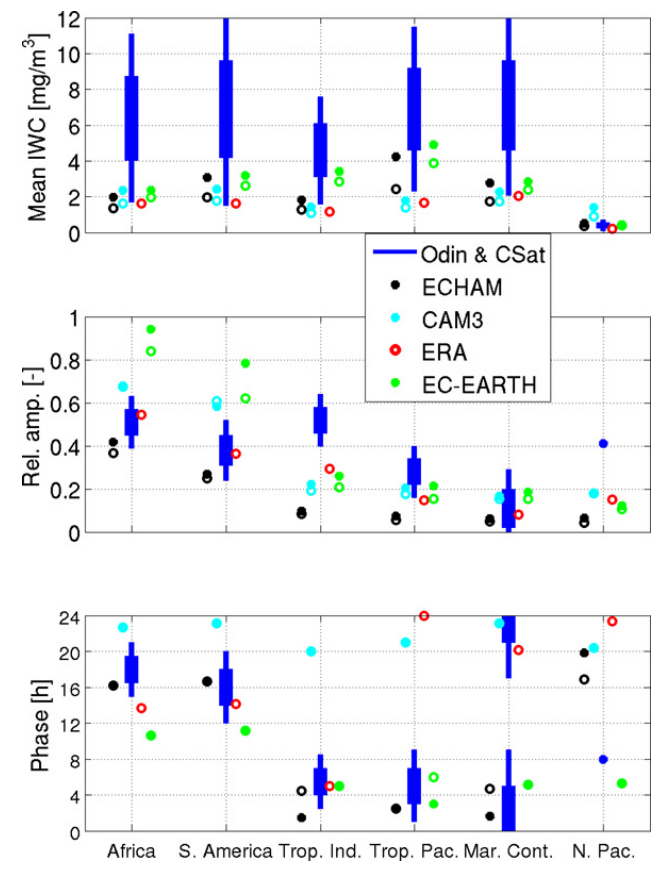

Fig. 7. Multi-year boreal winter and spring observed and simulated IWC diurnal variations around $190 \mathrm{hPa}$ for the regions defined in Fig. 2. The thick part of the blue lines corresponds to $\pm 1-\sigma$ and the thin part to $\pm 2-\sigma$ of the satellite estimates. The filled dots and circles represents model total cloud ice mass and in-cloud ice mass, respectively (see text for clarity). Observed amplitude and phase for the N. Pacific region are just indicative (Table 2).

data sources. This indicates that the IFS is more dependent on measurements over the tropical land region, than over the ocean regions.

The CAM3 results shown here are consistent with the results of Rasch et al. (2006) who studied the tropical transient activity of the hydrological cycle simulated by CAM3 by comparing model output with Tropical Rainfall Measuring Mission precipitation estimates and Global Cloud Imagery cloud brightness temperatures (Salby et al., 1991). They concluded that the transient aspects of convection in CAM3 were too weak and that the ratio of stratiform to convective rainfall was too low (by a factor of between 4 and 5). These conclusions are consistent with an earlier study using Community Climate System Model version 2 by Dai and Trenberth (2004) who hypothesised that moist convection in the model occurred too frequently and lasted too long, removing water vapour prematurely and too efficiently.

\subsection{Ice water content diurnal variations}

Figure 7 shows measured and modelled diurnal variations of IWC. A direct comparison between observations and model output is complicated by the fact that the measured and modelled IWC represents different quantities (see Sect. 2). However, in Fig. 7 model results for both the prognostic IWC 
(in-cloud ice mass) and total IWC (prognostic + diagnostic IWC or precipitating ice mass) are included. However, this is not the case for the ERA-interim data, which only contains prognostic IWC, and no data on precipitating ice is available. The North Pacific region is excluded from the discussion below as it basically contains no ice mass.

The in-cloud ice constitutes $60-90 \%$ of the total ice mass in this altitude region, according to the models. A much higher fraction of the cloud ice is found as precipitation at lower altitudes (not shown). If any difference exists, it should be expected that the relative amplitude is higher for total than in-cloud ice. The models also show this feature, with the exception of CAM over South America. However, in general, the models give limited differences for the relative amplitudes and the phases between ice-cloud and total ice.

Although most mean IWC values from the models are within the observed 2- $\sigma$ uncertainty, they are outside the 1- $\sigma$ uncertainty (biased low), except EC-EARTH over the tropical ocean regions. The low bias of the ERA-Interim data is not surprising given that this data set represents only smaller ice particles as described above. Even though the models total IWC values are in general lower than the measured values, the relative geographical variation are fairly consistent with the measurement data. For example, CAM 3 and ECHAM values are approximately a factor of 2-3 lower than the best measurement estimate for all regions considered.

The derived relative amplitudes are in fair agreement with ERA except over the Tropical Indian region, where the estimated amplitude is greater. Over ocean regions the models tend to underestimate the amplitude, while EC-EARTH and CAM3 overestimate the amplitude over land (in relative terms). Over the maritime continent, where the diurnal variation is relatively weak, the models and measurements agree. EC-EARTH and ERA produce fairly consistent amplitudes except over tropical land.

The modelled phases of CAM3 show little difference between land and ocean regions and do not match the measurements except over the Maritime Continent. Assuming the diurnal cycle of IWC is strongly linked to convective activity, these results tend to imply that the timing of tropical convection in CAM3 is poorly simulated although the measurement data here are insufficient to conclusively confirm this. Rasch et al. (2006) showed that CAM3 tended to produce maxima in tropical precipitation and liquid water path that were a few hours earlier than seen in observations over both oceans and land.

ECHAM and EC-Earth phases show a better agreement with the measurements, but some deviations can be noted. For example, EC-Earth has a phase that is significantly too early over both Africa and South America. The measurements give a RHi peak approximately 6 hours after IWC for the two land regions. This phase difference is lower in ECEarth, while it is higher in ECHAM with 12 and $7 \mathrm{~h}$ for Africa and South America, respectively. The CAM RHi/IWC phase differences for Africa and South America compare rea- sonably well with the observations but the timing of both the IWC and RHi peaks occurs later than observed. Over the two pure ocean regions with substantial IWC (Tropical Indian and Pacific), the results (excluding CAM) indicate that RHi and IWC peak at roughly the same time (around 05:00 h).

The relative timing of the RHi and IWC peaks is an indicator of the processes important in moistening the tropical upper troposphere. From the results shown here, there appears to be a difference in the characteristics of this moistening process over tropical land masses compared to tropical ocean regions which the models have difficulty capturing.

\subsection{Discussion}

An assessment of the measurement uncertainties has been made, and these values have, in detail, been mapped to error estimates for the variables describing the diurnal cycles (Sect. 3.3). The quality of this error estimation is critical for any possible conclusion that can be drawn from the model comparison. Conversely, the comparison can be an aid to judge the initial assumptions, and a repeated discussion of the uncertainty assessment is meaningful.

Aura MLS and Odin-SMR could have a deviating sensitivity for RHi at most dry and humid conditions, but there is no case where one instrument is above the other one for both passages (Fig. 3). That is, the measurements give a single diurnal maximum for all of the six regions. This shows that any overall systematic errors are small, or are (coincidentally) common for the two instruments. The high consistency with ERA (Fig. 6) suggests the earlier, or a combination of the two points. Accordingly, the 1- $\sigma$ uncertainty of $10 \%$ RHi (for both instruments) is with high probability not an underestimation. This judgement includes the different effects due to cloud interference. A quantitative estimation of this point is very difficult. A discussion for Aura MLS is found in Read et al. (2007). The MLS and SMR retrieval approaches are affected by clouds in very different ways and no obvious common impact has been identified. Accordingly, the error correlation between MLS and SMR RHi is here set to zero.

A bias of one of the instruments, that is identical for ascending and descending passages (i.e. correlation 1), has low impact on measured diurnal amplitude and phase. The main cause for errors not following this pattern should be cloud interference. To incorporate this effect, the error correlation between the two passages is here set to 0.9. This is potentially a too optimistic assumption, and the errors for amplitude and phase could be underestimated. However, maybe the simplest verification of these error estimates is to note that the deviations between these and earlier determined RHi phases are within the error margins.

The analysis for IWC is more simple as the error budget is dominated by a single issue: the particle size distribution. A $40 \%(1-\sigma)$ uncertainty should be a conservative estimate. In addition, the alternative CloudSat retrievals (Sect. 2.2.2) 
makes the analysis of error correlations relatively straightforward, and the confidence in the error assessment should be relatively high. There is, though, one exception, the amplitude and phase estimates for the N. Pacific region were rejected due to sensitivity aspects (Table 2).

It should be clear that a more detailed view of the diurnal cycles has been obtained by combining MLS/CloudSat with Odin-SMR. The information gained has not been determined in any quantitative way, but it is noted that a single sun-synchronous satellite samples the diurnal cycle at the Nyquist limit - if the diurnal variations can be described completely by a single harmonics as in Eq. (1). The maximum (and only) frequency is then $1 / 24 \mathrm{~h}^{-1}$ and the sampling frequency is $1 / 12 \mathrm{~h}^{-1}$. The measurements will give a lower bound on the diurnal amplitude, but it can be as low as zero. In this hypothetical case, the diurnal cycle would be determined fully by adding a second satellite, as long as it is in another orbit and all the observations are error-free. The diurnal cycles of water have more complicated structures, thus containing higher order harmonics (Jin et al., 2009), and even two satellites are, in principle, not sufficient.

\section{Conclusions}

There is a limited amount of information about the water budget and its variations in the upper troposphere. Previous measurement studies of clouds and humidity in this altitude layer have primarily been based on infrared sensors. Such sensors are not ideal for studying the amount of ice in thick clouds. In this study a combination of observations from microwave and sub-mm instruments (CloudSat, Aura-MLS, and Odin-SMR) is used to study the diurnal cycle of water in the tropical upper troposphere. All three instruments are placed in polar sun-synchronous orbits with tropical local observation times around 1:30 a.m. and p.m. for CloudSat and AURA-MLS and 6:00 a.m. and p.m. for Odin-SMR. The atmospheric layer considered is centred around $190 \mathrm{hPa}$ and parameters examined are relative humidity w.r.t.ice (RHi) and ice water content (IWC).

First and foremost, it is found that observations of average RHi from Odin-SMR and AURA-MLS are in good agreement with differences of only a few \% RHi. Furthermore, IWC retrievals, based on identical micro-physical assumptions, from Odin-SMR and CloudSat are also found to be in good agreement. Differences between the datasets are believed to be mainly an effect of diurnal variations. The results are accompanied by a detailed error analysis.

Estimates of relative IWC diurnal variations with high accuracy are obtained. Over tropical land regions an afternoon peak is observed, and over ocean regions an early morning maximum is observed. Over the maritime continent, a relatively high mean IWC value is observed throughout the day. The observed IWC phases coincide with the peak of the oc- currence frequency of deep convective clouds reported by Hong et al. (2006).

Most significant diurnal RHi variations are found over tropical land regions, with the maximum occurring around midnight, approximately $6 \mathrm{~h}$ after the IWC maximum. Over tropical oceanic regions RHi variations are less significant, but the observations indicate a maximum in the early morning.

Observed diurnal variations were compared to output from three climate models (EC-EARTH, ECHAM, and CAM3) and ERA-Interim. Average RHi values derived from SMR and MLS were found to be in excellent agreement with the ERA data, but all models were found for some points to deviate from these observations. A straightforward measurement-model IWC comparison was not possible as the measured and modelled cloud ice mass represent different quantities. The amount of "snow" had to be estimated from diagnostic parameters of the models. Model output was in some instances found to deviate from the observed 2- $\sigma$ uncertainty. For example, EC-EARTH was found to be in a fair agreement with the measurements over ocean regions, but with a lower consistency over land regions. Furthermore, the modelled phases of CAM3 showed a little difference between land and ocean regions and did not, for most cases, match the measurements. Although most modelled mean IWC values are within the observed 2- $\sigma$ uncertainty, modelled IWC is likely to be biased low (outside 1- $\sigma$ ).

Significant differences in tropical upper tropospheric water variables between observations and models have been presented and discussed. This analysis points to shortcomings in the models considered here but the measurement data are insufficient to evaluate all the relevant processes controlling RHi and IWC in the tropical upper troposphere. Therefore it is outside the scope of this work to investigate the reasons for disagreement between the models and the measurements. A full evaluation of the models focusing on processes including, amongst other things, the strength, depth and timing of tropical convection, the accuracy of vertical transport and the interaction between these processes and the large scale dynamics is required to understand the reasons for the model discrepancies. This is left for further studies.

Acknowledgements. This work has been funded by the Swedish National Graduate School of Space Technology at Luleå Technical University and the Swedish National Space Board.

Edited by: T. J. Dunkerton 


\section{References}

Austin, R. T., Heymsfield, A. J., and Stephens, G. L.: Retrieval of ice cloud microphysical parameters using the CloudSat millimeter-wave radar and temperature, J. Geophys. Res., 114, D00A23, doi:10.1029/2008JD010049, 2009.

Bonan, G. B., Oleson, K. W., Vertenstein, M., Levis, S., Zeng, X., Dai, Y., Dickinson, R. E., and Yang, Z.-L.: The land surface climatology of the Community Land Model coupled to the NCAR Community Climate Model, J. Climate, 15, 3123-3149, 2002.

Boville, B. A., Rasch, P. J., Hack, J. J., and McCaa, J. R.: Representation of clouds and precipitation processes in the Community Atmosphere Model (CAM3), J. Climate, 19, 2184-2198, 2005.

Briegleb, B. P., Bitz, C. M., Hunke, E. C., Lipscomb, W. H., Holland, M. M., Schramm, J. L., and Moritz, R. E.: Scientific description of the sea ice component in the Community Climate System Model, Version Three, Tech. Rep. Technical Report NCAR/TN-463+STR, National Center for Atmospheric Research, Boulder, CO 80307-3000, USA, 2004.

Chung, E. S., Sohn, B. J., Schmetz, J., and Koening, M.: Diurnal variation of upper tropospheric humidity and its relations to convective activities over tropical Africa, Atmos. Chem. Phys., 7, 2489-2502, doi:10.5194/acp-7-2489-2007, 2007.

Collins, W. D., Rasch, P. J., Boville, B. A., Hack, J. J., McCaa, J. R., and co authors: The formulation and atmospheric simulation of the Community Atmospheric Model Version 3 (CAM3), J. Climate, 9, 2144-2161, 2006.

Dai, A. and Trenberth, K. E.: The diurnal cycle and its depiction in the community climate system model, J. Climate, 17, 930-951, 2004.

Ekström, M. and Eriksson, P.: Altitude resolved ice-fraction in the uppermost tropical troposphere, Geophys. Res. Lett., 35, L13822, doi:10.1029/2008GL034305, 2008.

Ekström, M., Eriksson, P., Rydberg, B., and Murtagh, D.: First Odin sub-mm retrievals in the tropical upper troposphere: Humidity and cloud ice signals, Atmos. Chem. Phys., 7, 459-469, doi:10.5194/acp-7-459-2007, 2007.

Ekström, M., Eriksson, P., Read, W. G., Milz, M., and Murtagh, D. P.: Comparison of satellite limb-sounding humidity climatologies of the uppermost tropical troposphere, Atmos. Chem. Phys., 8, 309-320, doi:10.5194/acp-8-309-2008, 2008.

Eriksson, P., Ekström, M., Rydberg, B., and Murtagh, D.: First Odin sub-mm retrievals in the tropical upper troposphere: ice cloud properties, Atmos. Chem. Phys., 7, 471-483, doi:10.5194/acp-7471-2007, 2007.

Eriksson, P., Ekström, M., Rydberg, B., Wu, D. L., Austin, R. T., and Murtagh, D. P.: Comparison between early Odin-SMR, Aura MLS and CloudSat retrievals of cloud ice mass in the upper tropical troposphere, Atmos. Chem. Phys., 8, 1937-1948, doi:10.5194/acp-8-1937-2008, 2008.

Garrett, K. J., Yang, P., Nasiri, S., Yost, C. R., and Baum, B. A.: Influence of cloud top height and geometric thickness on MODIS infrared-based cirrus cloud retrieval, J. Appl. Meteor. Clim., 48, 818-832, 2009.

Harries, J. E.: Physics of the Earth's radiative energy balance, Contemp. Phys., 41, 309-322, 2000.

Held, I. M. and Soden, B. J.: Water vapour feedback and global warming, Annu. Rev. Energy Environ., 25, 441-475, 2000.

Hong, G., Heygster, G., and Rodriguez, C. A. M.: Effect of cirrus clouds on the diurnal cycle of tropical deep convective clouds, J.
Geophys. Res., 111, D06209, doi:10.1029/2005JD006208, 2006.

Horváth, A. and Soden, B. J.: Lagrangian diagnostics of tropical deep convection and its effect upon upper-tropospheric humidity, J. Climate, 21, 1013-1028, doi:10.11175/2007JCLI1786.1, 2008.

Hurrell, J. W., Hack, J. J., Shea, D., Caron, J. M., and Rosinski, J. M.: A new sea surface temperature and sea ice boundary data set for the Community Atmosphere Model, J. Climate, 21, 51455153, 2008.

IPCC: Climate Change 2007: The physical science basis. Contribution of Working Group I to the Fourth Assessment Report of the Intergovernmental Panel on Climate Change, Cambridge University Press, Cambridge, UK, 2007.

Jin, S., Luo, O. F., and Gleason, S.: Characterization of diurnal cycles in ZTD from a decade of global GPS observations, J. Geodynam., 83, 537-5451, doi:10.1007/s00190-008-0264-3, 2009.

John, V. O. and Soden, B. J.: Does convectively-detrained air cloud ice enhance water vapor feedback?, Geophys. Res. Lett., 33, D20701, doi:10.1029/2006GL027620, 2006.

Liu, C. and Zipser, E. J.: Diurnal cycles of precipitation, clouds, and lightning in the tropics from 9 years of TRMM observations, Geophys. Res. Lett., 35, L04 819, doi:10.1029/2007GL032437, 2008a.

Liu, C. and Zipser, E. J.: Implications of the differences between daytime and nighttime CloudSat observations over the tropics, J. Geophys. Res., 113, D00A04, doi:10.1029/2008JD009783, 2008b.

Liu, C. and Zipser, E. J.: Implications of the day versus night differences of water vapor, carbon monoxide, and thin cloud observations near the tropical tropopause, J. Geophys. Res., 114, D09303, doi:10.1029/2008JD011524, 2009.

Livesey, N. J., Snyder, W. V., Read, W. G., and Wagner, P.: Retrieval algorithms for the EOS Microwave Limb Sounder (MLS), IEEE Trans. Geosci. Remote Sens., 44, 1144-1155, doi:10.1109/ TGRS.2006.872327, 2006.

Locatelli, J. D. and Hobbs, P. V.: Fall speeds and masses of solid precipitation particles, J. Geophys. Res., 79, 2185-2197, 1974.

Lohmann, U. and Hoose, C.: Sensitivity studies of different aerosol indirect effects in mixed-phase clouds, Atmos. Chem. Phys., 9, 8917-8934, doi:10.5194/acp-9-8917-2009, 2009.

Lohmann, U. and Roeckner, E.: Design and performance of a new cloud microphysics scheme developed for the ECHAM general circulation model, Clim. Dynam., 12, 557-572, 1996.

Lohmann, U., Stier, P., Hoose, C., Ferrachat, S., Kloster, S., Roeckner, E., and Zhang, J.: Cloud microphysics and aerosol indirect effects in the global climate model ECHAM5-HAM, Atmos. Chem. Phys., 7, 3425-3446, doi:10.5194/acp-7-3452-2007, 2007.

Lohmann, U., Spichtinger, P., Jess, S., Peter, T., and Smit, H.: Cirrus cloud formation and ice supersaturated regions in a global climate model, Env. Res. Lett., 3, 045022, doi:10.1088/1748-9326/ 3/4/045022, 2008.

McFarquhar, G. M. and Heymsfield, A. J.: Parameterization of tropical cirrus ice crystal size distribution and implications for radiative transfer: Results from CEPEX, J. Atmos. Sci., 54, $2187-$ 2200, 1997.

Murtagh, D., Frisk, U., Merino, F., Ridal, M., Jonsson, A., Stegman, J., Witt, G., Eriksson, P., Jiménez, C., Megie, G., de La Noë, J., Ricaud, P., Baron, P., Pardo, J. R., Hauchcorne, A., Llewellyn, 
E. J., Degenstein, D. A., Gattinger, R. L., Lloyd, N. D., Evans, W. F. J., McDade, I. C., Haley, C., Sioris, C., von Savigny, C., Solheim, B. H., McConnell, J. C., Strong, K., Richardson, E. H., Leppelmeier, G. W., Kyrölä, E., Auvinen, H., and Oikarinen, L.: An overview of the Odin atmospheric mission, Can. J. Phys., 80, 309-319, 2002.

Oleson, K. W., Dai, Y., Bonan, G. B., Bosilovich, M., Dickinson, R., Dirmeyer, P., Hoffman, F., Houser, P., Levis, S., Niu, G.-Y., Thornton, P., Vertenstein, M., Yang, Z. L., and Zeng, X.: Technical description of the Community Land Model (CLM), Tech. Rep. Technical Report NCAR/TN-461+STR, National Center for Atmospheric Research, Boulder, CO 80307-3000, USA, 2004.

Rasch, P. J. and Kristjansson, J. E.: A comparison of the CCM3 model climate using diagnosed and predicted condensate parameterizations, J. Climate, 11, 1587-1614, 1998.

Rasch, P. J., Stevens, M. J., Ricciardulli, L., Dai, A., Negri, A., Wood, R., Boville, B. A., Eaton, B., and Hack, J. J.: A characterization of tropical transient activity in the CAM3 atmospheric hydrologic cycle, J. Climate, 19, 2222-2242, 2006.

Read, W. G., Lambert, A., Bacmeister, J., Cofield, R. E., Christensen, L. E., Cuddy, D. T., Daffer, W. H., Drouin, B. J., Fetzer, E., Froidevaux, L., Fuller, R., Herman, R., Jarnot, R. F., Jiang, J. H., Jiang, Y. B., Kelly, K., Knosp, B. W., Kovalenko, L. J., Livesey, N. J., Liu, H.-C., Manney, G. L., Pickett, H. M., Pumphrey, H. C., Rosenlof, K. H., Sabounchi, X., Santee, M. L., Schwartz, M. J., Snyder, W. V., Stek, P. C., Su, H., Takacs, L. L., Thurstans, R. P., Vömel, H., Wagner, P. A., Waters, J. W., Webster, C. R., Weinstock, E. M., and Wu, D. L.: Aura Microwave Limb Sounder upper tropospheric and lower stratospheric $\mathrm{H}_{2} \mathrm{O}$ and relative humidity with respect to ice validation, J. Geophys. Res., 112, D24S35, doi:doi:10.1029/2007JD008752, 2007.

Rydberg, B., Eriksson, P., Buehler, S. A., and Murtagh, D. P.: NonGaussian Bayesian retrieval of tropical upper tropospheric cloud ice and water vapour from Odin-SMR measurements, Atmos. Meas. Tech., 2, 621-637, doi:10.5194/amt-2-621-2009, 2009.

Salby, M. L., Hendon, H. H., Woodberry, K., and Tanaka, K.: Analysis of global cloud imagery from multiple satellites, Bull. Amer. Meteor. Soc., 72, 467-480, 1991.

Sherwood, S. C., Roca, R., Weckwerth, T. M., and Andronova, N. G.: Tropospheric water vapor, convection and climate, Rev. Geophys., 48, RG2001, doi:10.1029/2009RG000301, 2010.

Slingo, J., Inness, P., Neale, R., Woolnough, S., and Yang, G. Y.: Scale interactions on diurnal to seasonal timescales and their relevance to model systematic errors, Ann. Geophys., 46, 139-155, doi:10.5194/angeo-46-139-2003, 2003.

Soden, B. J.: The diurnal cycle of convection, clouds, and water vapor in the tropical upper troposphere, Geophys. Res. Lett., 27 , 2173-2176, 2000.

Soden, B. J.: The impact of tropical convection and cirrus on upper tropospheric humidity: A Lagrangian analysis of satellite measurements, Geophys. Res. Lett., 31, L20104, doi:10.1029/ 2004GL020980, 2004.

Soden, B. J. and Bretherton, F. P.: Upper tropospheric relative humidity from the GOES $6.7 \mu \mathrm{m}$ channel: Method and climatology for July 1987, J. Geophys. Res., 98, 16669-16688, 1993.

Sohn, B. J., Schmetz, J., and Chung, E. S.: Moistening processes in the tropical upper troposphere observed from Meteosat measurements, J. Geophys. Res., 113, D13109, doi:10.1029/ 2007JD009527, 2008.
Stephens, G. L., Vane, D. G., Boain, R. J., Mace, G. G., Sassen, K., Wang, Z. E., Illingworth, A. J., O’Connor, E. J., Rossow, W. B., Durden, S. L., Miller, S., Austin, R. T., Benedetti, A., and Mitrescu, C.: The CloudSat mission and the A-train - A new dimension of space-based observations of clouds and precipitation, Bull. Amer. Meteor. Soc., 83, 1771-1790, 2002.

Stier, P., Feichter, J., Kinne, S., Kloster, S., E.Vignati, Wilson, J., Ganzeveld, L., Tegen, I., Werner, M., Balkanski, Y., Schulz, M., Boucher, O., Minikin, A., and Petzold, A.: The aerosol-climate model ECHAM5-HAM, Atmos. Chem. Phys., 5, 1125-1156, doi:10.5194/acp-5-1125-2005, 2005.

Sundqvist, H., Berge, E., and Kristjansson, J. E.: Condensation and cloud parameterization studies with a mesoscale numerical weather prediction model, Mon. Weather Rev., 117, 1641-1657, 1989.

Tian, B., Soden, B. J., and Wu, X.: Diurnal cycle of convection, clouds, and water vapor in the tropical upper troposphere: Satellites versus a general circulation model, J. Geophys. Res., 109, D10101, doi:10.1029/2003JD004117, 2004.

Tiedtke, M.: Representation of clouds in large-scale models, Mon. Weather Rev., 121, 3040-3061, 1993.

Tompkins, A. M., Gierens, K., and Rädel, G.: Ice supersaturation in the ECMWF integrated forecast system, Q. J. Roy. Meteorol. Soc., 133, 53-63, 2007.

Uppala, S., Kållberg, P., Simmons, A., Andrae, U., da Costa Bechtold, V., Fiorino, M., Gibson, J., Haseler, J., Hernandez, A., Kelly, G., Li, X., Onogi, K., Saarinen, S., Sokka, N., Allan, R., Andersson, E., Arpe, K., Balmaseda, M., Beljaars, A., van de Berg, L., Bidlot, J., Bormann, N., Caires, S., Chevallier, F., Dethof, A., Dragosavac, M., Fisher, M., Fuentes, M., Hagemann, S., Holm, E., Hoskins, B., Isaksen, L., Janssen, P., Jenne, R., McNally, A., Mahfouf, J.-F., Morcrette, J.-J., Rayner, N., Saunders, R., Simon, P., Sterl, A., Trenberth, K., Untch, A., Vasiljevic, D., Viterbo, P., and Woollen, J.: The ERA-40 re-analysis, Q. J. Roy. Meteorol. Soc., 131, 2961-3012, doi:10.1256/qj.04.176, 2005.

Waliser, D. E., Li, J.-L. F., Woods, C. P., Austin, R. T., Bacmeister, J., Chern, J., Genio, A. D., Jiang, J. H., Kuang, Z., Meng, H., Minnis, P., Platnick, S., Rossow, W. B., Stephens, G. L., SunMack, S., Tao, W.-K., Tompkins, A. M., Vane, D. G., Walker, C., and Wu, D.: Cloud ice: a climate model challenge with signs and expectations of progress, J. Geophys. Res., 114, D00A21, doi:10.1029/2008JD010015, 2009.

Waters, J. W., Froidevaux, L., Harwood, R. S., Jarnot, R. F., Pickett, H. M., Read, W., Siegel, P. H., Cofield, R. E., Filipiak, M. J., Flower, D. A., Holden, J. R., Lau, G. K., Livesey, N. J., Manney, G. L., Pumphrey, H. C., Santee, M. L., Wu, W. L., Cuddy, D. T., Lay, R. R., Loo, M. S., Perun, V. S., Schwartz, M. J., Stek, P., Thurstans, R. P., Boyles, M. A., Chandra, K. M., Chavez, M. C., Chen, G. S., Chudasama, B. V., Dodge, R., Fuller, R. A., Girard, M. A., Jiang, J. H., Jiang, Y. B., Knosp, B. W., LaBelle, R., Lam, J. C., Lee, K. A., Miller, D., Oswald, J. E., Patel, N. C., Pukala, D. M., Quintero, O., Scaff, D. M., Snyder, W. V., Tope, M. C., Wagner, P., and Walch, M.: The Earth Observing System Microwave Limb Sounder (EOS MLS) on the Aura satellite, IEEE Trans. Geosci. Remote Sens., 44, 1075-1092, 2006.

Wu, D. L., Austin, R. T., Deng, M., Durden, S. L., Heymsfield, A. J., Jiang, J. H., Lambert, A., Li, J.-L., Livesey, N. J., McFarquhar, G. M., Pittman, J. V., Stephens, G. L., Tanelli, S., Vane, D. G., and Waliser, D. E.: Comparisons of global cloud ice from 
MLS, CloudSat, and correlative data sets, J. Geophys. Res., 114, D00A24, doi:10.1029/2008JD009946, 2009.

Yang, G. Y. and Slingo, J.: The diurnal cycle in the tropics, Mon. Weather Rev., 129, 784-801, 2001.

Zelinka, M. D. and Hartmann, D. L.: Response of humidity and clouds to tropical deep convection, J. Climate, 22, 2389-2404, 2009.

Zelinka, M. D. and Hartmann, D. L.: Why is longwave cloud feedback positive?, J. Geophys. Res., 115, D16117, doi:10.1029/ 2010JD013817, 2010.
Zhang, G. J. and McFarlane, N. A.: Sensitivity of climate simulations to the parameterization of cumulus convection in the Canadian Climate Centre general circulation model, Atmos.-Ocean, 33, 407-446, 1995.

Zhang, M., Lin, W., Bretherton, C. B., Hack, J. J., and Rasch, P. J.: A modified formulation of fractional stratiform condensation rate in the NCAR Community Atmosphere Model (CAM2), J. Geophys. Res., 108(D1), 4035, doi:10.1029/2002JD002523, 2003. 